\title{
Brown adipose tissue volume in healthy lean south Asian adults compared with white Caucasians: a prospective, case-controlled observational study
}

\author{
Citation for published version (APA): \\ Bakker, L. E., Boon, M. R., van der Linden, R. A., Arias-Bouda, L. P., van Klinken, J. B., Smit, F., \\ Verberne, H. J., Jukema, J. W., Tamsma, J. T., Havekes, L. M., van Marken Lichtenbelt, W. D., Jazet, I. \\ M., \& Rensen, P. C. (2014). Brown adipose tissue volume in healthy lean south Asian adults compared \\ with white Caucasians: a prospective, case-controlled observational study. The Lancet Diabetes \& \\ Endocrinology, 2(3), 210-217. https://doi.org/10.1016/S2213-8587(13)70156-6
}

\section{Document status and date: \\ Published: 01/01/2014}

DOI:

10.1016/S2213-8587(13)70156-6

\section{Document Version:}

Publisher's PDF, also known as Version of record

\section{Document license:}

Taverne

Please check the document version of this publication:

- A submitted manuscript is the version of the article upon submission and before peer-review. There can be important differences between the submitted version and the official published version of record.

People interested in the research are advised to contact the author for the final version of the publication, or visit the DOI to the publisher's website.

- The final author version and the galley proof are versions of the publication after peer review.

- The final published version features the final layout of the paper including the volume, issue and page numbers.

Link to publication

\footnotetext{
General rights rights.

- You may freely distribute the URL identifying the publication in the public portal. please follow below link for the End User Agreement:

www.umlib.nl/taverne-license

Take down policy

If you believe that this document breaches copyright please contact us at:

repository@maastrichtuniversity.nl

providing details and we will investigate your claim.
}

Copyright and moral rights for the publications made accessible in the public portal are retained by the authors and/or other copyright owners and it is a condition of accessing publications that users recognise and abide by the legal requirements associated with these

- Users may download and print one copy of any publication from the public portal for the purpose of private study or research.

- You may not further distribute the material or use it for any profit-making activity or commercial gain

If the publication is distributed under the terms of Article 25fa of the Dutch Copyright Act, indicated by the "Taverne" license above, 


\title{
Q Brown adipose tissue volume in healthy lean south Asian adults compared with white Caucasians: a prospective, case-controlled observational study
}

\author{
Leontine E H Bakker*, Mariëtte R Boon*, Rianne A D van der Linden, Lenka Pereira Arias-Bouda, Jan B van Klinken, Frits Smit, Hein J Verberne, \\ J Wouter Jukema, Jouke T Tamsma, Louis M Havekes, Wouter D van Marken Lichtenbelt, Ingrid M Jazet*, Patrick C N Rensen*
}

\section{Summary}

Lancet Diabetes Endocrinol 2014; 2: 210-17

Published Online November 12, 2013 http://dx.doi.org/10.1016/ S2213-8587(13)70156-6

See Comment page 185

*Authors contributed equally Department of Endocrinology and Metabolic Diseases (LE H Bakker MD, M R Boon MSc, RA D van der Linden Bsc, JTTamsma MD, Prof L M Havekes PhD, I M Jazet MD,

Prof P ( N Rensen PhD), Einthoven Laboratory for Experimental Vascular Medicine (M R Boon, ProfJW Jukema MD, L M Havekes, PC N Rensen, J B van Klinken PhD), Department of Human Genetics (J B van Klinken), and

Department of Cardiology (JW Jukema, L M Havekes), Leiden University Medical Center, Leiden, Netherlands; Department of Nuclear

Medicine, Rijnland Hospital, Leiderdorp, Netherlands (LP Arias-Bouda MD, F Smit MD); Department of Nuclear Medicine, Academic Medical Center, Amsterdam, Netherlands (HJ Verberne MD);

TNO-Biosciences, Leiden, Netherlands (L M Havekes); and Department of Human Biology, NUTRIM School for Nutrition,

Toxicology and Metabolism, Maastricht University Medical Center, Maastricht, Netherlands (W D van

Marken Lichtenbelt PhD)

Correspondence to:

Miss Mariëtte R Boon, Department of Endocrinology and Metabolic Diseases, Post Zone C7Q, Leiden University Medical Center, PO Box 9600 , 2300 RC Leiden, Netherlands m.r.boon@lumc.nl

Background Individuals of south Asian origin have a very high risk of developing type 2 diabetes compared with white Caucasians. We aimed to assess volume and activity of brown adipose tissue (BAT), which is thought to have a role in energy metabolism by combusting fatty acids and glucose to produce heat and might contribute to the difference in incidence of type 2 diabetes between ethnic groups.

Methods We enrolled Dutch nationals with south Asian ancestry and matched Caucasian participants at The Rijnland Hospital (Leiderdorp, Netherlands). Eligible participants were healthy lean men aged 18-28 years, and we matched groups for BMI. We measured BAT volume and activity with cold-induced ${ }^{18} \mathrm{~F}$-fluorodeoxyglucose (18F-FDG) PET CT scans, and assessed resting energy expenditure, non-shivering thermogenesis, and serum parameters. This study is registered with the Netherlands Trial Register, number 2473.

Findings Between March 1, 2013, and June 1, 2013, we enrolled 12 participants in each group; one Caucasian participant developed hyperventilation after 18F-FDG administration, and was excluded from all cold-induced and BAT measurements. Compared with Caucasian participants, south Asian participants did not differ in age (mean 23.6 years [SD 2.8] for south Asians vs 24.6 years [2.8] for Caucasians) or BMI $\left(21.5 \mathrm{~kg} / \mathrm{m}^{2}[2.0] v s 22.0 \mathrm{~kg} / \mathrm{m}^{2}\right.$ [1.6]), but were shorter $(1.74 \mathrm{~m} \mathrm{[0.06]}$ vs $1.85 \mathrm{~m} \mathrm{[0.04])}$ and lighter $(65.0 \mathrm{~kg}$ [8.5] vs $75 \cdot 1 \mathrm{~kg}[7 \cdot 2])$. Thermoneutral resting energy expenditure was 1297 kcal per day (SD 123) in south Asian participants compared with 1689 kcal per day (193) in white Caucasian participants (difference $-32 \%, \mathrm{p}=0.0008$ ). On cold exposure, shiver temperature of south Asians was $2 \cdot 0^{\circ} \mathrm{C}$ higher than Caucasians $(\mathrm{p}=0.0067)$ and non-shivering thermogenesis was increased by $20 \%$ in white Caucasians $(\mathrm{p}<0.0001)$ but was not increased in south Asians. Although the maximum and mean standardised uptake values of 18F-FDG in BAT did not differ between groups, total BAT volume was lower in south Asians (188 mL [SD 81]) than it was in Caucasians (287 mL [169]; difference -34\%, p=0 04). Overall, BAT volume correlated positively with basal resting energy expenditure in all assessable individuals $(\beta=0 \cdot 44, p=0 \cdot 04)$.

Interpretation Lower resting energy expenditure, non-shivering thermogenesis, and BAT volumes in south Asian populations might underlie their high susceptibility to metabolic disturbances, such as obesity and type 2 diabetes. Development of strategies to increase BAT volume and activity might help prevent and treat such disorders, particularly in south Asian individuals.

Funding Dutch Heart Foundation (2009T038) and Dutch Diabetes Research Foundation (2012.11.1500).

\section{Introduction}

South Asian individuals originate from the Indian subcontinent and constitute a fifth of the world's population. The risk of development of type 2 diabetes and its related complications is very high in native and migrant south Asians compared with people of white Caucasian descent, and prevalence is increasing. Moreover, type 2 diabetes occurs at a younger age and lower BMI in south Asians than Caucasians, ${ }^{2,3}$ and the risk of complications related to diabetes is increased in this group. ${ }^{4,5}$ The underlying cause of this excess risk is incompletely understood, but might involve a common disadvantageous metabolic phenotype, consisting of central obesity, insulin resistance, and dyslipidaemia. ${ }^{6,7} \mathrm{~A}$ common assumption is that ethnic susceptibility towards a disturbed energy homoeostasis (eg, reduced oxidation of glucose and fatty acids by mitochondria) underlies this phenotype. $^{8}$

Recently, brown adipose tissue (BAT) has been identified to have a role in energy homoeostasis in humans. ${ }^{9-12}$ In contrast to white adipose tissue, BAT burns triglycerides and glucose to generate heat through a process called mitochondrial uncoupling. ${ }^{13}$ A main stimulator for BAT activation is cold and repeated cold exposure leads to recruitment of BAT in healthy humans. ${ }^{14}$ BAT volume and activity-as assessed after exposure to cold by use of 18F-fluorodeoxyglucose (18F-FDG) PET CT scans-are inversely related to BMI and percentage of body fat in adult humans, suggesting an inverse association between BAT and obesity. ${ }^{11,15,16}$ Besides a clear role for BAT in triglyceride metabolism, ${ }^{17}$ this tissue is also thought to contribute to glucose 
homoeostasis, especially in resting conditions when glucose use by skeletal muscle is minimal. ${ }^{18}$ Notably, BAT seems to contribute to non-shivering thermogenesis ${ }^{12,16}$ and fully activated BAT in humans has been estimated to contribute up to $15-20 \%$ of total energy expenditure. ${ }^{13}$

Because BAT is involved in total energy expenditure and clearance of serum triglycerides and glucose, thereby protecting against metabolic disturbances, we postulated that a low BAT volume or activity might underlie the disadvantageous metabolic phenotype and susceptibility to type 2 diabetes in south Asians. Therefore, we investigated resting energy expenditure and BAT volume and activity in young healthy lean south Asian men and matched white Caucasians (hereafter referred to as Caucasians), by use of a ventilated hood technique and cold-induced 18F-FDG PET CT scans. In addition, we examined the effect of cold exposure on non-shivering thermogenesis, thermoregulation, and plasma lipid levels.

\section{Methods \\ Study design and participants}

We enrolled Dutch south Asian participants (ie, individuals born in the Netherlands with two south Asian parents) and matched Dutch Caucasian participants at The Rijnland Hospital in Leiderdorp in the Netherlands. We recruited eligible healthy men aged 18-28 years with a lean body type $\left(\mathrm{BMI}<25 \mathrm{~kg} / \mathrm{m}^{2}\right)$ via local advertisements. Participants underwent medical screening to obtain their medical history and a physical examination, blood chemistry tests, and an oral glucose tolerance test to exclude individuals with type 2 diabetes according to the American Diabetes Association 2010 criteria. Other exclusion criteria were rigorous exercise ( $>10 \mathrm{~h}$ of exercise per week), smoking, and recent bodyweight change $(>3 \mathrm{~kg}$ weight gain or loss within 3 months before enrolment). Participants were matched for BMI with a pairwise approach. The study was approved by the Medical Ethical Committee of the Leiden University Medical Center and undertaken in accordance with the principles of the revised Declaration of Helsinki. All volunteers provided written informed consent.

\section{Procedures}

We assessed participants in the morning after a $10 \mathrm{~h}$ overnight fast and after $24 \mathrm{~h}$ without exercise. Participants wore standardised clothing, consisting of a $\mathrm{T}$ shirt and boxer shorts. We determined body composition by means of dual-energy x-ray absorptiometry (iDXA, GE Healthcare, UK). We inserted a cannula in the left antecubital vein for blood sampling and injection of 18F-FDG. The appendix contains further details on study techniques.

To activate BAT, we applied two water perfused cooling mattresses (Blanketrol III, Cincinnati Sub-Zero Products, Cincinnati, OH, USA). ${ }^{16}$ During the procedure participants stayed in a clinical examination room. The protocol started with a baseline period of $1 \mathrm{~h}$ in thermoneutral condition, after which participants were exposed to mild cold. Because the onset temperature of shivering is very variable and dependent on the individual (eg, because of differences in body composition), ${ }^{13}$ we used an individualised cooling protocol to ensure maximum non-shivering thermogenesis, and thus a maximum level of BAT activity, for each participant. Cooling started at $32^{\circ} \mathrm{C}$ and temperature was gradually decreased until shivering occurred. Temperature was then raised by $3-4^{\circ} \mathrm{C}$ and the cooling period of $2 \mathrm{~h}$ was started (defined as $\mathrm{t}_{\text {cold }}=0 \mathrm{~min}$ ). If shivering occurred, the temperature was raised by $1^{\circ} \mathrm{C}$ until shivering stopped. We detected shivering visually or it was reported by participants. After $1 \mathrm{~h}$ of cooling $\left(\mathrm{t}_{\text {cold }}=60 \mathrm{~min}\right)$, we injected $2 \mathrm{MBq} / \mathrm{kg}$ 18F-FDG intravenously. To exclude artifacts of muscle activity, participants were instructed to lie still. We collected venous blood when participants were thermoneutral and when they were in a cold-induced condition ( $\mathrm{t}_{\text {cold }}=110 \mathrm{~min}$ ) and did indirect calorimetry with a ventilated hood (Oxycon Pro, CareFusion, Germany) in thermoneutral condition and $\mathrm{t}_{\text {cold }}$ of 80-110 min. After $2 \mathrm{~h}$ of cooling ( $\mathrm{t}_{\text {cold }}=120 \mathrm{~min}$ ) we did 18F-FDG PET CT imaging to quantify BAT volume an activity.

Imaging was done with a PET CT scanner (Gemini TF PET CT, Philips, Netherlands) as described previously (appendix). ${ }^{11}$ Imaging started with a low-dose CT scan (effective dose $2 \mathrm{mSv}$ ), immediately followed by a PET scan. We used the CT scan for attenuation correction and localisation of the 18F-FDG uptake sites. Both image sets were reconstructed in transaxial, coronal, and sagittal images with a slice thickness of $4 \mathrm{~mm}$. PET CT images were interpreted by a nuclear medicine physician (LPAB) and a researcher (MRB or RADL), who were masked to patient group, with dedicated software (Hermes Hybrid Viewer, Hermes Medical Solutions, Sweden). We quantified BAT activity and detectable volume in the region of interest by autocontouring the BAT areas with a set threshold (standardised uptake value [SUV] of $2 \cdot 0 \mathrm{~g} / \mathrm{mL})$.

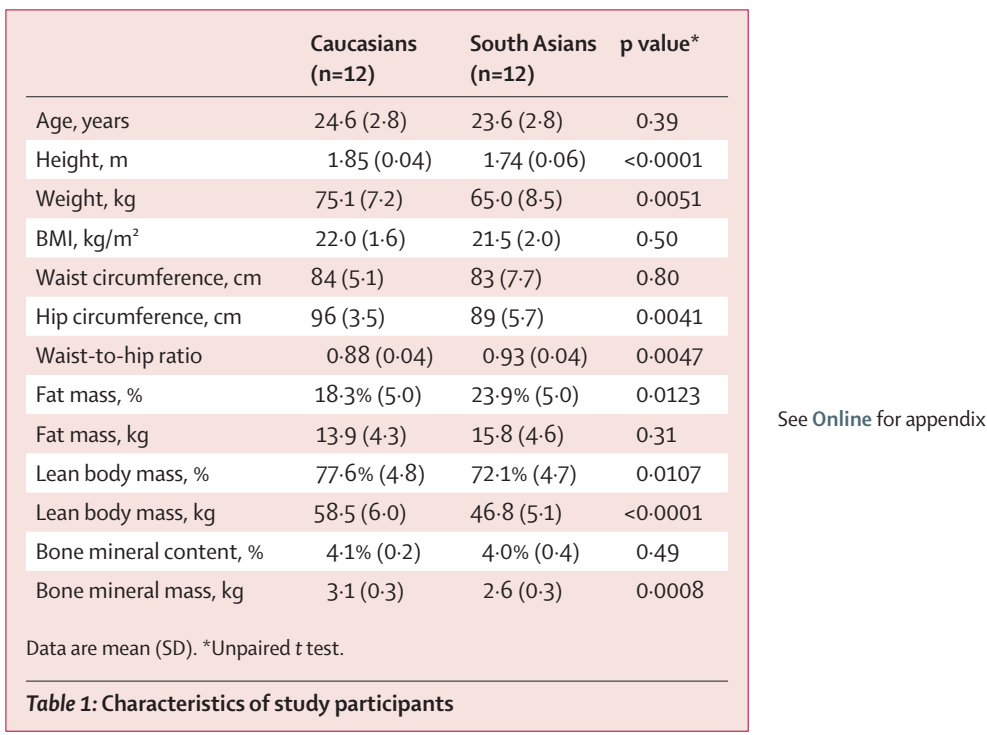


To register temperature changes, we measured core body temperature in the small intestine at $1 \mathrm{~min}$ intervals with an ingestible telemetric capsule (Jonah, BMedical, Australia). Measurement of core temperature did not work in two participants (one in each group). We also measured skin temperature at $1 \mathrm{~min}$ intervals by wireless iButtons (Maxim, USA) placed at different positions on the skin. ${ }^{19}$

We report total detectable BAT volume in $\mathrm{mL}$ and BAT activity in terms of SUV (the ratio of activity in $\mathrm{kBq} / \mathrm{mL}$ within the region of interest and the injected activity [kBq] per bodyweight [g]). We established maximum SUV $\left(\mathrm{SUV}_{\text {max }}\right)$ in $\mathrm{g} / \mathrm{mL}$ and the average SUV $\left(\mathrm{SUV}_{\text {mean }}\right)$ in $\mathrm{g} / \mathrm{mL}$ within the volume of interest. We assessed energy expenditure, respiratory quotient, and rates of substrate oxidation every $1 \mathrm{~min}$ as described previously. ${ }^{20,21} \mathrm{We}$ measured skin temperatures according to the 14 point International Organization for Standardization method (appendix). ${ }^{19}$

We used enzymatic kits to measure serum triglyceride concentrations (Roche Diagnostics, Netherlands) serum glucose concentrations (Instruchemie, Delfzijl, Netherlands) and free fatty acid concentrations (Wako Chemicals, Germany).

\section{Statistical analysis}

Normally distributed data are shown as mean (SD) and non-normally distributed data are shown as median (IQR). We applied a mixed-effects model to assess mean differences before and after cold exposure within and between groups, and to determine differences in the effect of cold exposure. We modelled groups and

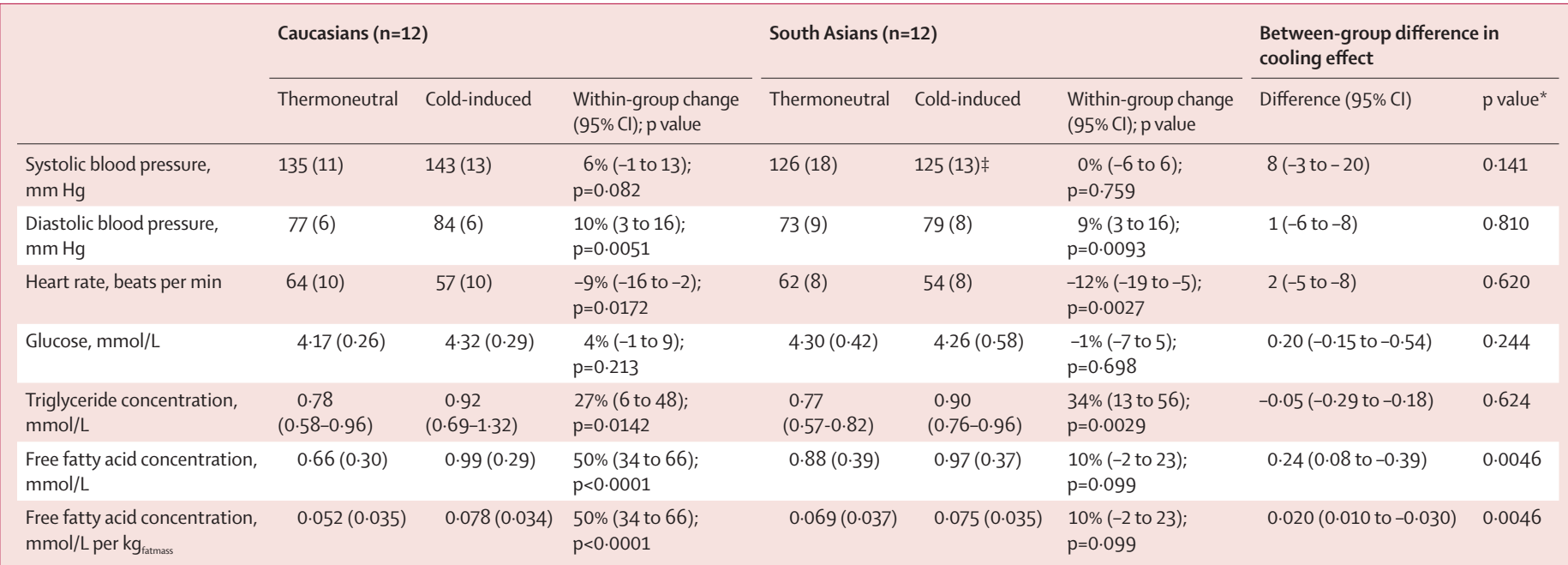

Data are mean (SD) or median (IQR), unless otherwise stated. All p values are based on a mixed model. ${ }^{*} \mathrm{p}$ value for cooling effect in the south Asian group vs Caucasian group. $\neq \mathrm{f}=0.0046$ for cold-induced value in the south Asian group vs the Caucasian group.

Table 2: Cardiovascular parameters and fasting serum levels in thermoneutral and cold-induced conditions

\begin{tabular}{|c|c|c|c|c|c|c|c|c|}
\hline & \multicolumn{3}{|l|}{ Caucasians ( $\mathrm{n}=12$ ) } & \multicolumn{3}{|l|}{ South Asians ( $n=12$ ) } & \multicolumn{2}{|c|}{$\begin{array}{l}\text { Between-group difference in } \\
\text { cooling effect }\end{array}$} \\
\hline & Thermoneutral & Cold-induced & $\begin{array}{l}\text { Within-group } \\
\text { change }(95 \% \mathrm{Cl}) \text {; } \\
\text { p value }\end{array}$ & Thermoneutral & Cold-induced & $\begin{array}{l}\text { Within-group } \\
\text { change }(95 \% \mathrm{Cl}) \text {; } \\
\text { p value }\end{array}$ & Difference $(95 \% \mathrm{Cl})$ & p value* \\
\hline $\begin{array}{l}\text { Resting energy expenditure, } \\
\text { kcal per day }\end{array}$ & $1689(193)$ & $2027(471)$ & $\begin{array}{l}20 \%(9 \text { to } 31) \\
p=0.0011\end{array}$ & $1297(123) \dagger$ & $1462(127) \ddagger$ & $\begin{array}{l}13 \%(-1 \% \text { to } \\
27 \%) ; p=0.072\end{array}$ & $171(-89$ to -430$)$ & 0.186 \\
\hline Lipid oxidation, $\mathrm{g} / \mathrm{min}$ & $0.063(0.024)$ & $0.092(0.040)$ & $\begin{array}{l}46 \%(24 \text { to } 70) \\
p<0.0001\end{array}$ & $0.049(0.009)$ & $0.062(0.014) \varsigma$ & $\begin{array}{l}26 \%(-7 \% \text { to } \\
46 \%) ; p=0.072\end{array}$ & $0.016(-0.004$ to -0.036$)$ & $0 \cdot 119$ \\
\hline Glucose oxidation, $\mathrm{g} / \mathrm{min}$ & $0.151(0.057)$ & $0.141(0.037)$ & $\begin{array}{l}-6 \%(-23 \text { to } 12) \\
p=0 \cdot 277\end{array}$ & $0.114(0.014) \boldsymbol{\Phi}$ & $0.111(0.036)$ & $\begin{array}{l}-0.3 \%(-25 \% \text { to } \\
24 \%) ; p=0.804\end{array}$ & $-0.011(-0.046$ to -0.025$)$ & 0.538 \\
\hline Respiratory quotient & $0.85(0.06)$ & $0.82(0.04)$ & $\begin{array}{l}-4 \%(-6 \text { to }-1) \\
p=0.0303\end{array}$ & $0.84(0.02)$ & $0.82(0.04)$ & $\begin{array}{l}-2 \%(-6 \% \text { to } \\
1 \%) ; p=0.128\end{array}$ & $-0.01(-0.05$ to -0.03$)$ & 0.577 \\
\hline
\end{tabular}

Data are mean (SD), unless otherwise stated. All p values are based on a mixed model. * $\mathrm{p}$ value for cooling effects in the south Asian group vs Caucasians. $† \mathrm{p}=0.0008$ for thermoneutral value in the South Asian group vs Caucasian group. $\neq \mathrm{p}<0.0001$ for cold-induced value in the South Asian group vs Caucasian group. $\$ \mathrm{p}=0.0058$ for cold-induced value in the South Asian group vs Caucasian group. I $\mathrm{p}=0.0285$ for thermoneutral value in the South Asian group vs Caucasian group. 


\begin{tabular}{|c|c|c|c|c|c|c|c|c|}
\hline & \multicolumn{3}{|c|}{ Caucasians ( $n=12$ ) } & \multicolumn{3}{|c|}{ South Asians ( $\mathrm{n}=12$ ) } & \multicolumn{2}{|c|}{$\begin{array}{l}\text { Between-group difference in } \\
\text { cooling effect }\end{array}$} \\
\hline & Thermoneutral & Cold-induced & $\mathrm{p}$ valuet & Thermoneutral & Cold-induced & p valuet & Difference $(95 \% \mathrm{Cl})$ & p value* \\
\hline Shiver temperature & .. & $8.9(1.5)$ & .. & .. & $10 \cdot 9(1 \cdot 8)$ & .. & .. & 0.0067 \\
\hline Cooling temperature &.$\cdot$ & $19 \cdot 8(2 \cdot 5)$ &.$\cdot$ &.$\cdot$ & $18 \cdot 7(2 \cdot 2)$ & .. &. & 0.271 \\
\hline Core temperature & $36.8(0.2)$ & $36 \cdot 6(0 \cdot 3)$ & 0.130 & $36 \cdot 6(0 \cdot 3)$ & $36 \cdot 8(0 \cdot 2)$ & 0.128 & $-0.4(-0.7$ to -0.0$)$ & 0.0339 \\
\hline Skin temperature & $33 \cdot 1(0.5)$ & $28 \cdot 6(1 \cdot 0)$ & $<0.0001$ & $33.4(0 \cdot 7)$ & $28.8(1.0)$ & $<0.0001$ & $0.1(-0.7$ to -0.8$)$ & 0.836 \\
\hline Proximal skin temperature & $34.4(0.4)$ & $30 \cdot 8(1 \cdot 0)$ & $<0.0001$ & $34 \cdot 4(0.4)$ & $31 \cdot 0(1 \cdot 1)$ & $<0.0001$ & $-0.2(-1.0$ to -0.5$)$ & 0.535 \\
\hline Distal skin temperature & $31.8(0.9)$ & $26 \cdot 3(1 \cdot 4)$ & $<0.0001$ & $32 \cdot 5(1 \cdot 3)$ & $26 \cdot 6(1 \cdot 5)$ & $<0.0001$ & $0.4(-0.7$ to -1.5$)$ & 0.482 \\
\hline Core to mean skin temperature gradient & $3.6(0.4)$ & $7.9(0.9)$ & $<0.0001$ & $3 \cdot 2(1.0)$ & $8 \cdot 1(1 \cdot 1)$ & $<0.0001$ & $-0.5(-1.4$ to -0.6$)$ & 0.643 \\
\hline Core to distal skin temperature gradient & $4.8(0.7)$ & $10 \cdot 0(1.4)$ & $<0.0001$ & $4.1(1.5)$ & $10 \cdot 2(1 \cdot 5)$ & $<0.0001$ & $-0.8(-2.2$ to -0.6$)$ & 0.236 \\
\hline
\end{tabular}

interventions as fixed effects and modelled participantspecific deviances from the group mean as random effects. We used unpaired $t$ tests to compare baseline characteristics and BAT parameters between groups. We used non-parametric tests (Wilcoxon signed-rank test for within-group analyses and Mann-Whitney tests for between-group analyses) when appropriate. We used ANCOVA to correct parameters for lean body mass. Linear regression analyses were done to identify correlations between variables. The significance level was set at $\mathrm{p}<0 \cdot 05$. We did not adjust for multiple testing. All statistical analyses were done with SPSS for Windows version 20.0.

This study is registered with the Netherlands Trial Register, number 2473.

\section{Role of the funding source}

This study was financed by the Dutch Diabetes Research Foundation (grant 2012.11.1500), the Dutch Heart Foundation (grant 2009T038), and the Board of Directors of the Leiden University Medical Center. These foundations were not involved in the collection, analysis, and interpretation of data, or writing of the manuscript. The corresponding author had full access to all the data in the study and had final responsibility for the decision to submit for publication

\section{Results}

Between March 1, 2013, and June 1, 2013, we enrolled 12 South Asian participants and 12 Caucasian participants. Mean age and BMI values did not differ between groups, but south Asian participants were shorter and lighter than were Caucasian participants (table 1). The percentage of fat mass was higher in south Asians than Caucasians and, consequently, the percentage of lean body mass was lower. Additionally, the waist-to-hip ratio was higher in south Asians than Caucasians. One Caucasian participant developed hyperventilation after 18 F-FDG administration, and was excluded from all cold-induced and BAT comparisons.

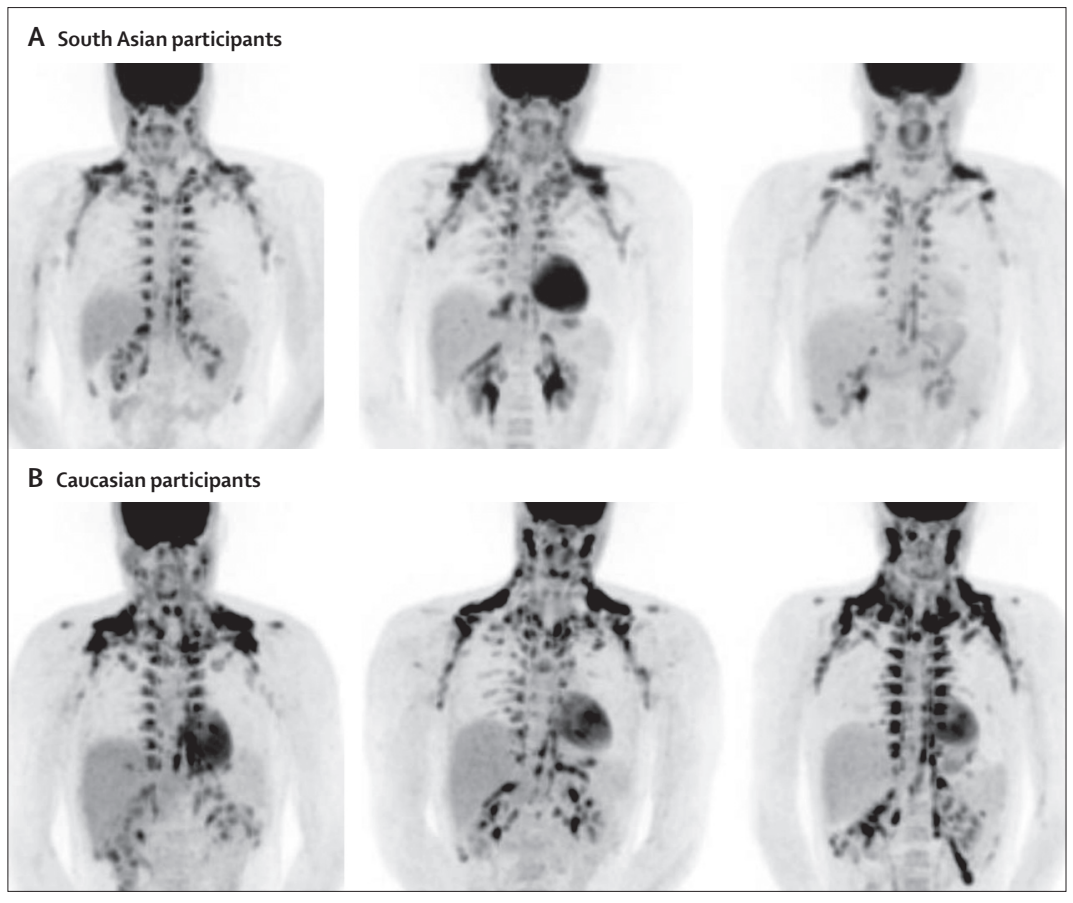

Figure 1: Brown adipose tissue activity as assessed by ${ }^{18} \mathrm{~F}$-fluorodeoxyglucose PET CT scans in three representative healthy young south Asian men (A) and matched Caucasians (B) Black areas show uptake of ${ }^{18} \mathrm{~F}$-fluorodeoxyglucose in brown adipose tissue, and other glucose-consuming tissues such as brain and heart, and to a lesser degree liver. Kidney calyces and ureters are visible due to clearance of the tracer.

Cold exposure increased diastolic blood pressure and decreased heart rate in both groups (table 2). Cold exposure did not seem to affect systolic blood pressure, but systolic blood pressure during cold exposure was significantly lower in south Asian participants than in Caucasian participants (table 2).

Fasting thermoneutral glucose and lipid concentrations did not differ between groups (table 2). Cooling did not affect serum glucose concentrations, but increased serum triglyceride concentrations in both groups. Of note, a significant cold-induced increase in serum free fatty acid concentrations was present in Caucasian 
participants, but not in south Asian participants. The ethnic difference in cold-induced free fatty acid release was even more pronounced after dividing serum free fatty acid levels by total fat mass, which is the main source of serum free fatty acid (table 2).

Before cooling, resting energy expenditure was 32\% lower in south Asians than it was in Caucasians (table 3). This difference persisted after correction for lean body mass with ANCOVA (intercept $177 \mathrm{kcal}$ per day [SD 173] vs 290 kcal per day [215]; $\mathrm{p}=0 \cdot 0316$; appendix). During cold exposure, non-shivering thermogenesis increased significantly in Caucasians (by 20\%; $1689 \mathrm{kcal}$ per day [SD 193] vs $2027 \mathrm{kcal}$ per day [471]; $\mathrm{p}<0 \cdot 0001)$, but not in south Asians (by 13\%; 1297 kcal per day [123] kcal per day vs 1462 [127]; $\mathrm{p}=0.09$ ) (appendix). Furthermore, cold exposure significantly increased lipid oxidation only in Caucasians, whereas glucose oxidation was not affected in either group (table 3 ). In line with this finding, cold exposure significantly decreased respiratory quotient in Caucasians only (table 3 ).

Despite an increased fat mass percentage, the temperature at which shivering started was higher in south Asians than it was in Caucasians (table 4). Due to individual fine-tuning of the environmental temperature during non-shivering thermogenesis, mean environmental cooling temperature did not differ between groups during the second half of cooling (table 4). Core temperature was not affected by cold exposure. Mean overall, proximal, and distal skin temperatures decreased substantially to much the same extent in both groups (table 4). Consequently, core to distal and core to mean skin temperature gradients were significantly higher during cooling, suggesting an insulative response in south Asian and Caucasian participants.

In $22(96 \%)$ of 23 assessable participants, active BAT was detected by 18 F-FDG uptake in the classic regions for this tissue (figure 1). ${ }^{15}$ The only participant who did not have cold-induced BAT activity was Caucasian and also had the lowest resting energy expenditure in that group. $\mathrm{SUV}_{\max }$ and $\mathrm{SUV}_{\text {mean }}$ in the volume of interest with metabolically active BAT did not differ between south Asian and Caucasian participants (figure 2). Notably, detectable BAT volume was substantially lower in south Asians (188 mL [SD 81]) than it was in Caucasians

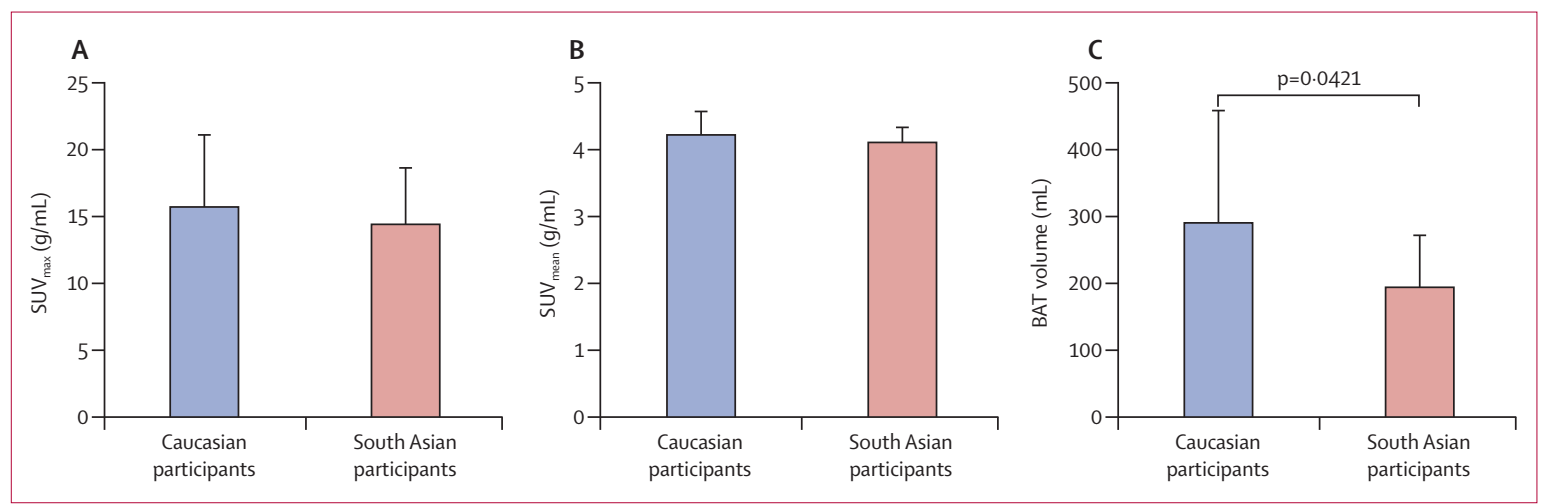

Figure 2: Brown adipose tissue activity and volume in healthy young south Asian men and matched Caucasians, assessed by ${ }^{18} \mathrm{~F}$-fluorodeoxyglucose PET CT scans Error bars show SD. (A) Maximum standardised uptake value $\left(\right.$ SUV $\left._{\text {max }}\right)$. (B) Mean standardised uptake value $\left(\right.$ SUV $\left._{\text {mean }}\right)$. (C) Total detectable brown adipose tissue volume. BAT=brown adipose tissue.

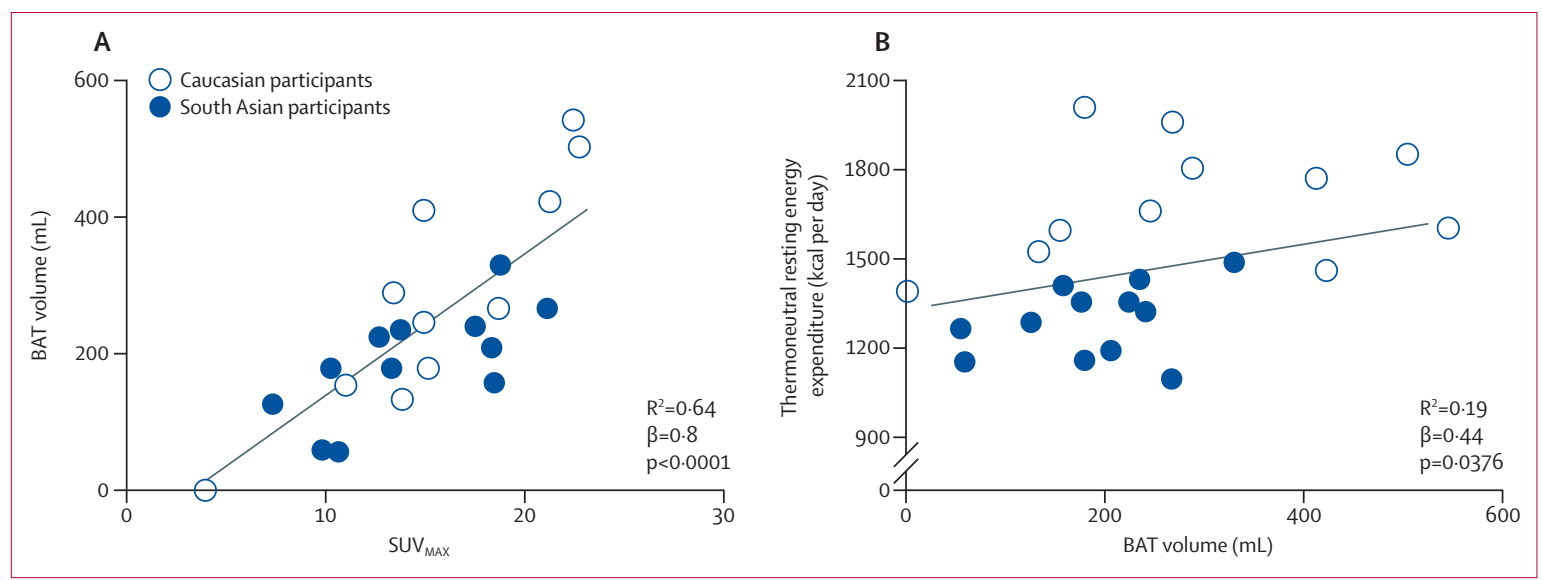

Figure 3: Correlations with brown adipose tissue

BAT volume in relation to SUV $\mathrm{max}_{\text {max }}(\mathrm{A})$ and thermoneutral resting energy expenditure (B). Correlations were determined with linear regression analysis. BAT=brown adipose tissue. SUV $_{\max }=$ maximum standardised update of ${ }^{18} \mathrm{~F}$-fluorodeoxyglucose. 
(287 mL [169]; difference -34\%, $\mathrm{p}=0 \cdot 04$ ), as shown in a representative sample of patients in figure 1.

Linear regression analysis showed a clear positive correlation between $\mathrm{SUV}_{\max }$ and BAT volume (figure 3). Furthermore, thermoneutral serum free fatty acid concentration correlated with BAT volume in Caucasian participants $\left(\mathrm{R}^{2}=0 \cdot 49, \beta=0 \cdot 70, \mathrm{p}=0 \cdot 02\right)$, but not in south Asian participants $\left(\mathrm{R}^{2}=0.0009, \quad \beta=0.03, \quad \mathrm{p}=0.97\right)$. Thermoneutral resting energy expenditure did not correlate with BAT volume in individual groups. However, with pooling of all participants, there was a weak but significant positive association between thermoneutral resting energy expenditure and BAT volume $\left(\mathrm{R}^{2}=0 \cdot 19\right.$, $\beta=0 \cdot 44, p=0 \cdot 038$; figure 3 ), strongly suggesting that BAT is involved in total energy metabolism.

\section{Discussion}

In our study, healthy, young, lean south Asian participants had lower resting energy expenditures than did equivalent Caucasians. Notably, the detectable volume of metabolically active BAT, which has previously been shown to significantly contribute to energy metabolism, ${ }^{11,15}$ was substantially lower in south Asian participants than Caucasians. These findings were corroborated by an increased shiver temperature and lower cold-induced non-shivering thermogenesis in south Asians compared with Caucasians.

We detected BAT in $96 \%$ of assessable participants, which corresponds to the proportions noted in previous studies (panel). ${ }^{11,23}$ Moreover, as reported previously, ${ }^{13,23}$ cold exposure in Caucasian participants resulted in increased serum free fatty acid concentrations, lipid oxidation, systolic blood pressure, and non-shivering thermogenesis (which aims to prevent a drop in core body temperature). In south Asians, all of these responses were less pronounced. Our previous study ${ }^{14}$ suggested that BAT, and not muscle, is responsible for nonshivering thermogenesis via mitochondrial uncoupling. Lean participants with detectable BAT activity have significantly higher non-shivering thermogenesis than those without detectable activity. ${ }^{12}$ Therefore, less BAT volume might underlie the smaller increase in nonshivering thermogenesis in south Asians; however, we did not identify a correlation between BAT volume and non-shivering thermogenesis, which has been shown previously, ${ }^{12,16,24}$ albeit not consistently. ${ }^{11,25}$

Because cold-induced increases in lipolysis and systolic blood pressure are mediated by sympathetic activation, the lower response in south Asians might be attributable to a lower cold-induced sympathetic activation. We cannot rule out the possibility that this change was attributable to the fact that south Asians were initially cooled from a somewhat higher initial shiver temperature, resulting in less sympathetic outflow. However, $\mathrm{SUV}_{\text {max }}$ and $\mathrm{SUV}_{\text {mean }}$ did not differ between groups, suggesting that BAT could be equally stimulated in all individuals by cold exposure. Thus, signs of lower sympathetic activation were only present in the white adipose tissue depot and the vasculature, and not in BAT. This finding can be explained because sympathetic outflow neurons towards various organs derive from different brain regions. ${ }^{26}$ A lower sympathetic response in south Asians might, at least in part, underlie their lower resting energy expenditure, because the reduced liberation of free fatty acids from white adipose tissue in plasma could have lowered the availability of free fatty acids for combustion by BAT, resulting in lower fat oxidation. Future studies would be needed to investigate a potentially different (organspecific) sympathetic response in south Asians and the potential link with resting energy expenditure.

South Asians had a significantly increased shivering temperature on cold exposure, despite their overall increased total percentage of fat mass compared with Caucasians. Conversely, obese participants have lower shivering temperatures than do lean participants because of increased insulation. ${ }^{16}$ An impaired capacity of BAT to contribute to total heat production might underlie the accelerated action of the muscles to produce heat by shivering in south Asians. This assumption is supported by a study of Ouellet and colleagues ${ }^{10}$ in which participants with high BAT volumes had reduced rates of shivering during cooling. However, we cannot exclude the possibility that the increased shivering temperature in south Asians could, at least in part, be influenced by their small body size and lower lean body mass.

It could be argued that low energy metabolism in south Asians is not be solely attributable to decreased BAT volume but also because of diminished oxidative metabolism in muscle. We obtained muscle biopsies from the same participants as in this study before and

\section{Panel: Research in context}

\section{Systematic review}

Individuals of south Asian origin have a very high risk of development of type 2 diabetes compared with white Caucasians. The underlying cause of this excess risk is incompletely understood, but might involve a common disadvantageous metabolic phenotype, consisting of central obesity, insulin resistance, and dyslipidaemia. Because brown adipose tissue (BAT) is involved in total energy expenditure and clearance of serum triglycerides and glucose, we postulated that a low BAT volume or activity might underlie the disadvantageous metabolic phenotype and susceptibility to type 2 diabetes in south Asians. We searched PubMed for articles published in English before Sept 11 2013, with the terms "south Asian" and "brown adipose tissue". We identified one article in which BAT was compared between south Asian and Caucasian individuals by use of a fixed cooling protocol. ${ }^{22}$

\section{Interpretation}

In our study, healthy lean south Asian men had lower BAT volumes and resting energy expenditures than did matched white Caucasians. This distinction might underlie the high susceptibility of south Asians to develop metabolic disturbances such as obesity and type 2 diabetes. These findings are clinically relevant because no treatment at present can diminish the disadvantageous metabolic phenotype and consequent development of metabolic disease in south Asians; targeting BAT might be a particularly promising approach for this population. 
after a short-term high-fat diet challenge, and did not observe differences in skeletal muscle insulin signalling or expression of genes involved in oxidative phosphorylation and mitochondrial biogenesis. ${ }^{27}$ Furthermore, food intake and levels of physical activity did not differ between south Asians and Caucasians. Thus, the lower resting energy expenditure which we found in south Asians is probably not a consequence of a lower food intake or lower levels of physical activity.

The question remains as to what mechanisms underlie the decreased BAT volume in south Asians. Because this decrease is noted in healthy young adults without differences in the degree of 18F-FDG uptake, as shown by equivalent $\mathrm{SUV}_{\text {max }}$ and $\mathrm{SUV}_{\text {mean }}$ values, a defect could have arisen in BAT differentiation. However, 18F-FDG uptake only represents glucose uptake by the tissue and not metabolism itself. Therefore, a potential dysfunction in oxidative metabolism in the tissue cannot be excluded and should be investigated further, for example with an ${ }^{11} \mathrm{C}$-acetate tracer as described previously ${ }^{10}$ or by study of BAT biopsies. The underlying cause of lower BAT volume in south Asians might be genetic (ie, blunted expression of signalling molecules involved in BAT differentiation), environmental (ie, clothing or heating), or a combination of the two.

Our study had limitations. Although our group size was in line with several landmark BAT studies ${ }^{9,11}$ and provided sufficient power to identify differences in detectable BAT volume between south Asians and Caucasians, the study may have been underpowered for some correlations. Strengths of our study included large number of measurements we did alongside 18F-FDG PET CT scans, such as indirect calorimetry and temperature records, and the use of a personalised cooling protocol with water-perfused cooling mattresses, which results in maximal BAT activity and detectable BAT volume in non-shivering conditions. ${ }^{13}$ This personalised cooling protocol might explain why in a recent study by Admiraal and colleagues, ${ }^{22}$ in which all participants were cooled in an air-cooled chamber with a stable temperature of $17^{\circ} \mathrm{C}$, no difference in BAT volume could be identified in south Asian compared with Caucasian participants. Because water has a higher heat transfer coefficient than air, water cooling results in more rapid cooling of participants and, possibly, an increased ability to detect BAT. Median BAT volume in Caucasian patients in the Admiraal study ${ }^{22}$ was only $16 \mathrm{~mL}$ compared with $287 \mathrm{~mL}$ in our study. Thus, the less-intense cooling protocol in that study might have underestimated BAT volumes in their study participants. Moreover, exposure of all participants to a stable room temperature of $17^{\circ} \mathrm{C}$ might have led to underestimation of BAT volume in Caucasian participants compared with south Asian participants, because Caucasians begin (according to our study) to shiver at lower temperatures. A possible drawback of the use of a personalised cooling protocol is that differences in environmental temperature could induce differences in BAT activity, because a strong positive association exists between environmental temperature and thermogenesis. ${ }^{28}$ However, we do not believe such differences arose in our study because $\mathrm{SUV}_{\text {max }}$ and $\mathrm{SUV}_{\text {mean }}$ did not differ between the groups, suggesting equal BAT activation.

This study has important clinical implications. Until now, little was known about the underlying mechanisms of the disadvantageous metabolic phenotype and the consequently high risk of type 2 diabetes in south Asians. Therefore, treatment options and, more importantly, preventive strategies are unfocused and of limited efficacy in south Asians. Increasing the volume or activity of BAT, resulting in increased clearance of glucose and fatty acids and increased total energy expenditure, might be of great therapeutic potential in this group. We recently showed that BAT can be recruited in humans following 10 days of cold intervention. ${ }^{14}$ Future studies should be directed towards the efficacy of this strategy, as well as other options, such as medication, to increase BAT volume or activity. These strategies might ultimately be useful for improving the metabolic phenotype in south Asians with type 2 diabetes or at high risk of developing the disease.

\section{Contributors}

LEHB and MRB contributed to conception and design of the study, the acquisition, analysis, and interpretation of data, and wrote the report. RADvdL contributed to acquisition, analysis, and interpretation of data and reviewed the report. JBvK contributed to analysis and interpretation of the data and reviewed the report. LPA-B, FS, and HJV researched the PET CT scan data and reviewed the report. JWJ, JTT, and LMH reviewed the report. WDvML contributed to conception and design of the study, interpretation of data, and reviewed and edited the report. IMJ and PCNR contributed to conception and design of the study, interpretation of data, and reviewed and edited the report. LEHB, MRB, IMJ, and PCNR are the guarantors of this work and, as such, had full access to all the data generated in the framework of the study and take responsibility for their integrity and the accuracy of their analysis. All authors have reviewed and approved the report.

Conflicts of interest

We declare that we have no conflicts of interest.

\section{Acknowledgments}

This work is financed by the Dutch Diabetes Research Foundation (grant 2012.11.1500 to PCNR and MRB). MRB is supported by the Board of Directors of the Leiden University Medical Center (LUMC) and PCNR is Established Investigator of the Netherlands Heart Foundation (grant 2009T038). We thank Roba Metals B V IJsselstein (Utrecht, Netherlands) for financial support. The Blanketrol III cooling device was kindly provided by FMH Medical (Veenendaal, Netherlands). We thank Bram Sinon and Tjerk Lugthart (Rijnland Hospital, Leiderdorp, Netherlands) for their excellent technical assistance.

\section{References}

1 Whiting DR, Guariguata L, Weil C, Shaw J. IDF diabetes atlas: global estimates of the prevalence of diabetes for 2011 and 2030 Diabetes Res Clin Pract 2011; 94: 311-21.

2 Bindraban NR, van Valkengoed IG, Mairuhu G, et al. Prevalence of diabetes mellitus and the performance of a risk score among Hindustani Surinamese, African Surinamese and ethnic Dutch: a cross-sectional population-based study. BMC Public Health 2008; 8: 271 .

3 Chiu M, Austin PC, Manuel DG, Shah BR, Tu JV. Deriving ethnic-specific BMI cutoff points for assessing diabetes risk. Diabetes Care 2011; 34: 1741-48. 
4 Chandie Shaw PK, Baboe F, van Es LA, van der Vijver JC, van de Ree MA, Rabelink TJ. South-Asian type 2 diabetic patients have higher incidence and faster progression of renal disease compared with Dutch-European diabetic patients. Diabetes Care 2006; 29: 1383-85.

5 Chaturvedi N, Fuller JH. Ethnic differences in mortality from cardiovascular disease in the UK: do they persist in people with diabetes? J Epidemiol Community Health 1996; 50: 137-39.

6 McKeigue PM, Shah B, Marmot MG. Relation of central obesity and insulin resistance with high diabetes prevalence and cardiovascular risk in south Asians. Lancet 1991; 337: 382-86.

7 Boon MR, Karamali NS, de Groot CJ, et al. E-Selectin is elevated in cord blood of south Asian neonates compared with Caucasian neonates. J Pediatr 2011; 160: 844-48.

8 Hall LML, Moran CN, Milne GR, et al. Fat oxidation, fitness and skeletal muscle expression of oxidative/lipid metabolism genes in south Asians: implications for insulin resistance? PLoS One 2010; 5: e14197.

9 Cypess AM, Chen YC, Sze C, et al. Cold but not sympathomimetics activates human brown adipose tissue in vivo. Proc Natl Acad Sci USA 2012; 109: 10001-05.

10 Ouellet V, Labbe SM, Blondin DP, et al. Brown adipose tissue oxidative metabolism contributes to energy expenditure during acute cold exposure in humans. J Clin Invest 2012; 122: 545-52.

11 Van Marken Lichtenbelt WD, Vanhommerig JW, Smulders NM, et al. Cold-activated brown adipose tissue in healthy men. N Engl J Med 2009; 360: 1500-08.

12 Yoneshiro T, Aita S, Matsushita M, et al. Brown adipose tissue, whole-body energy expenditure, and thermogenesis in healthy adult men. Obesity 2012; 19: 13-16.

13 Van Marken Lichtenbelt WD, Schrauwen P. Implications of nonshivering thermogenesis for energy balance regulation in humans. Am J Physiol Regul Integr Comp Physiol 2011; 301: R285-96

14 Van der Lans AA, Hoeks J, Brans B, et al. Cold acclimation recruits brown fat and increases nonshivering thermogenesis. J Clin Invest 2013; 123: 3395-403.

15 Cypess AM, Lehman S, Williams G, et al. Identification and importance of brown adipose tissue in adult humans. N Engl J Med 2009; 360: 1509-17.
16 Vijgen GH, Bouvy ND, Teule GJ, Brans B, Schrauwen P, van Marken Lichtenbelt WD. Brown adipose tissue in morbidly obese subjects. PLoS One 2011; 6: e17247.

17 Bartelt A, Bruns OT, Reimer R, et al. Brown adipose tissue controls triglyceride clearance. Nat Med 2011; 17: 200-05.

18 Stanford KI, Middelbeek RJ, Townsend KL, et al. Brown adipose tissue regulates glucose homeostasis and insulin sensitivity. J Clin Invest 2013; 123: 215-23.

19 van Marken Lichtenbelt WD, Daanen HA, Wouters L, et al. Evaluation of wireless determination of skin temperature using iButtons. Physiol Behav 2006; 88: 489-97.

20 Simonson DC, DeFronzo RA. Indirect calorimetry: methodological and interpretative problems. Am J Physiol 1990; 258: E399-412.

21 Feurer I, Mullen JL. Beside measurement of resting energy expenditure and respiratory quotient via indirect calorimetry. Nutr Clin Prac 1986; 1: 43-49.

22 Admiraal WM, Verberne HJ, Karamat FA, Soeters MR, Hoekstra JB Holleman F. Cold-induced activity of brown adipose tissue in young lean men of South-Asian and European origin. Diabetologia 2013; 56: 2231-37.

23 Vosselman MJ, Brans B, Van der Lans AA, et al. Brown adipose tissue activity after a high-calorie meal in humans. Am J Clin Nutr 2013; 98: 57-64.

24 Orava J, Nuutila P, Lidell M, et al. Different metabolic responses of human brown adipose tissue to activation by cold and insulin. Cell Metab 2011; 14: 272-79.

25 Vosselman MJ, van der Lans AA, Brans B, et al. Systemic beta-adrenergic stimulation of thermogenesis is not accompanied by brown adipose tissue activity in humans. Diabetes 2012; 6: 3106-13

26 Llewellyn-Smith IJ. Anatomy of synaptic circuits controlling the activity of sympathetic preganglionic neurons. J Chem Neuroanat 2009; 38: 231-39.

27 Bakker LEH, van Schinkel LD, Guigas B, et al. A 5-day high fat high calorie diet impairs insulin sensitivity in healthy, young south Asian men but not in Caucasian men. Diabetes (in press).

28 Cannon B, Nedergaard J. Nonshivering thermogenesis and its adequate measurement in metabolic studies. J Exp Biol 2011; 214: $242-53$. 